\title{
REGIONAL RESILIENCE-BASED NATURAL RESOURCE MANAGEMENT PLANNING IN AUSTRALIA: THE NAMOI CATCHMENT EXPERIENCE
}

\author{
FRANCESCA ANDREONI \\ BelTempo Natural Resource Management, Australia
}

\begin{abstract}
In 2010 Australia introduced the first resilience-based regional (catchment-based) natural resource management plans. The Namoi Catchment Management Authority was one of the first regions to apply this approach. The approach has since been applied across regions throughout Australia to varying degrees and with varying levels of formal institutional and policy support. This paper looks in detail at the Namoi Catchment as a case study showing how a resilience assessment of the Catchment was undertaken based on the resilience alliance workbook. Conceptual models of social-ecological system function were developed around the themes of land, water, biodiversity and people and the relevant critical underpinning assets were identified. Conceptual models were also developed for the subregional scale. An evidence base was established, and resilience concepts synthesized into a set of principles in plain English to assist with engaging all stakeholders and communities in the process. This paper also explores the approach used to develop implementation plans based on the resulting Catchment Action Plan (using contribution to overall system function, proximity to threshold, trend, temporal risk to threshold being breached along with an assessment of triple bottom line outcomes, achievability, time lag to benefit and cost). The resilience-based planning approach resulted in a much more focussed and simplified set of priorities to ensure maximum future choices for the region, allowing all stakeholders to focus on the few key issues that, if not addressed, potentially undermine the region's capacity to cope with future shocks and challenges. An adaptive management strategy and triggers for review were also essential, with a revised set of plans produced in 2013. This paper also examines the benefits and challenges associated with using a resilience-based planning approach at the regional scale (based on the Namoi Catchment experience) and to what extent the outcomes achieved have persisted through subsequent reforms and planning processes.

Keywords: resilience planning, resilience assessment, natural resource management, adaptive management, Namoi Catchment, reform.
\end{abstract}

\section{INTRODUCTION}

Natural resource management plans in Australia are based on regions or river catchments. Natural resources are governed by a complex array of laws and policies. Catchment Action Plans (CAPs) are designed to coordinate action and facilitate collaboration. The Namoi Catchment is a rich agricultural region in the north west of the state of New South Wales, Australia defined by the water catchment of the Namoi River (Fig. 1). It covers an area of $42,000 \mathrm{~km}^{2}$ and stretches over $350 \mathrm{~km}$ from east to west. The area is home to 100,000 people. The region's climate, along with summer dominant rainfall, allows for cropping and pasture growth all year round across most of the area. Agriculture is a key industry for the catchment with a rapidly emerging coal, coal seam gas and mineral resource extraction industry. Balancing the economic development pressures, particularly through extractive industries, with improved resilience and sustainability of the Catchment as a whole is a key challenge for planners and managers in the region.

The Namoi Catchment Management Authority (CMA) was one of the first regional natural resource management organisations in Australia to develop a resilience-based CAP as a part of a state-wide pilot program involving two regions (Namoi, and Central West 

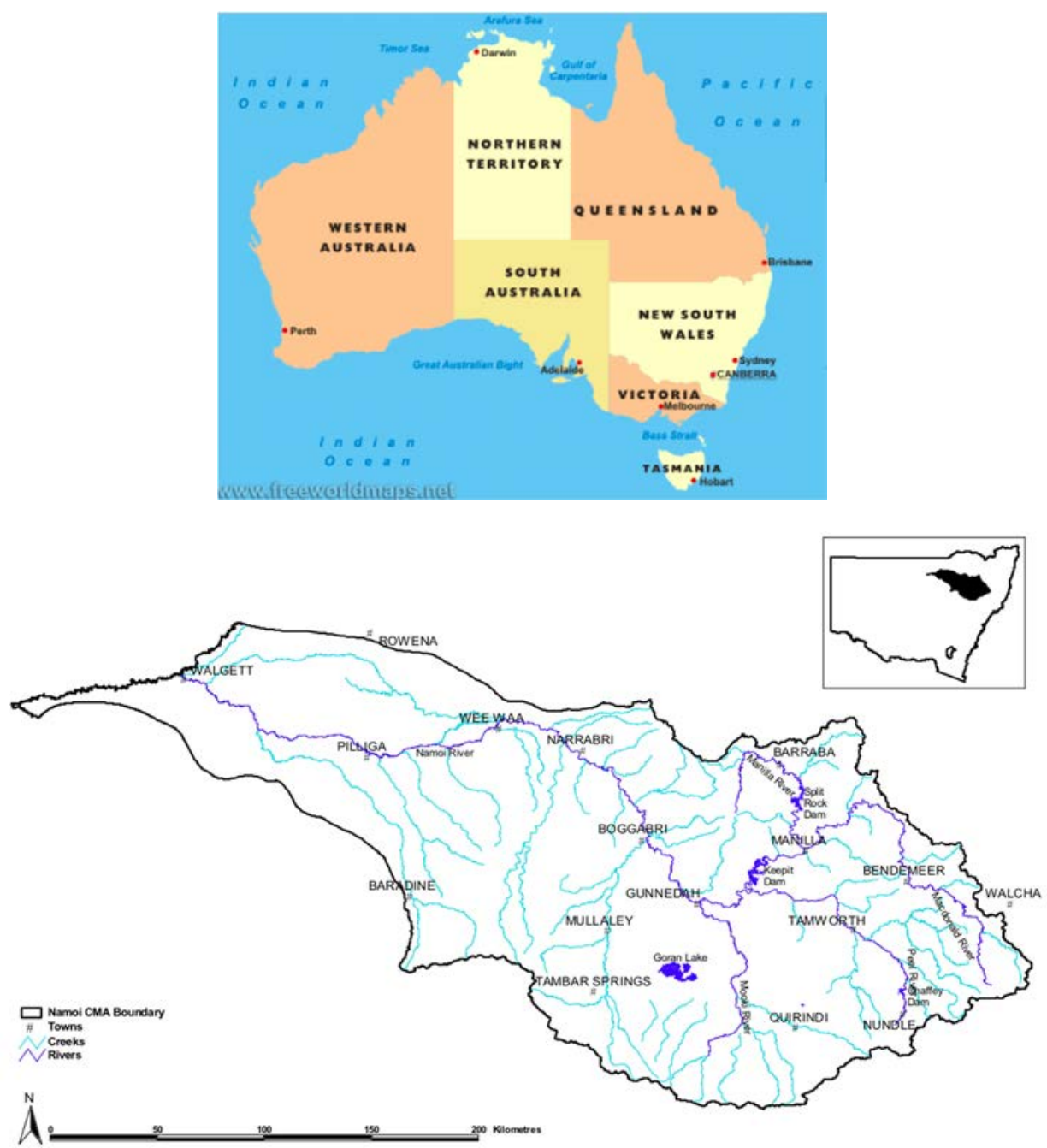

Figure 1: Namoi Catchment, NSW, Australia. (Source: Namoi CMA [1].)

Catchments). This initiative was driven by the understanding that traditional planning paradigms and approaches were not working - and the natural resources base was continuing to decline despite all investment and efforts to date.

CAPs are designed to be a whole of government (non-regulatory) document that outlines what steps to be taken to ensure ongoing and sustainable use of catchment natural resources. The Goulburn-Broken Catchment in the state of Victoria was the first to undertake a resilience assessment of any sort to inform Catchment planning. Resilience as a conceptual framework was then picked up by the State of New South Wales (NSW) particularly through the Natural Resources Commission which oversaw Catchment Action Plans. The Namoi resilience-based CAP was part of the 1st of 3 waves of resilience based natural resource management planning in Australia (Sellberg et al. [2]). Subsequent reforms in NSW have moved away from a resilience approach - although practitioners and planners who have been 
exposed to resilience assessment and planning continue to use it as part of their approach either formally or informally depending on the level of institutional support. This pattern is also reflected across Australia more broadly.

\section{DEVELOPING THE RESILIENCE-BASED NAMOI CATCHMENT ACTION PLAN}

The resilience based Namoi CAP was developed using the following steps. Throughout the process both formal and informal discussions were undertaken with a range of experts, including State Government agency researchers and managers, independent experts and local government representatives. This was done to test and check the approach, thinking and assumptions; and to gauge reactions and responses from key catchment stakeholder groups and natural resource management and resilience experts.

\subsection{Review of previous Catchment Action Plan and resilience theory}

The first step was a review of the outgoing CAP. The previous 2005 CAP was considered "dated", unwieldy and inadequate to address emerging issues such as climate change, new policy directions and investor preferences. To test assumptions, and ensure any flaws from the previous CAP were not rolled forward into the updated version, an initial internal review of progress on CAP actions, and relevance of Catchment and Management targets was undertaken and shared with the catchment community. It was also determined that targets in the new CAP would need to be directly aligned with State targets, and developed so as to facilitate measurement of progress and status. The challenge of aligning a resilience-based CAP (using a systems approach) with more linear and siloed traditional State targets was addressed as shown in Fig. 2.

A review of resilience theory and assessment methodology was undertaken through literature review and direct consultation with recognised experts in Australia and internationally. The Resilience Alliance workbook "Assessing and managing resilience in social-ecological systems: A practitioner's handbook" (Resilience Alliance [3]) was reviewed and adapted to the specific needs of the Namoi CAP development process. One of the key variations was to initially use expert workshops to define assets and to gather a large amount of information as quickly as possible. A set of key resilience principles were developed in plain English specifically for the Namoi Catchment to facilitate community understanding and engagement.

\subsection{Resilience assessment of the Namoi Catchment}

A resilience assessment of the entire catchment was undertaken to understand the complexity and resilience of the social-ecological systems of the Namoi Catchment and inform the development of the Namoi CAP (Namoi CMA [4]). The assessment initially focussed on specified resilience (i.e. resilience to specific changes that can be identified) with general resilience assessment and three sub-regional resilience assessments undertaken to inform subsequent updates. Previous research, evaluations and assessments undertaken across the catchment were used to understand what the catchment community valued. Policy positions and legislative platforms were also considered as a reflection of community attitudes and values.

Each of the four CAP themes (water, land, biodiversity and people) were initially analysed separately. Whilst this was not strictly in keeping with a resilience approach, it was necessary to ensure a result that would align with required State targets (see Fig. 2), and provided a structure for workshops and consultation. A series of workshops were held bringing together 
researchers, managers, private and public sector researchers and experts, and government agency representatives. For each theme, the workshops defined underpinning assets, and elicited information about their current state and trends, drivers of change, threats, available evidence base, any known or suspected thresholds, controlling variables and implications of continuing trends, along with any linkages with other assets and themes. The people theme was approached slightly differently. The impacts of continuing biophysical trends on people and their response were considered with a focus on adaptive capacity and general resilience. Following the workshops, further research was undertaken to fill any gaps and to document available evidence regarding trends, thresholds and conceptual models. For each theme a conceptual model of how assets interact was developed (Fig. 3) along with an overall conceptual model of the Catchment as a whole (Fig. 4).

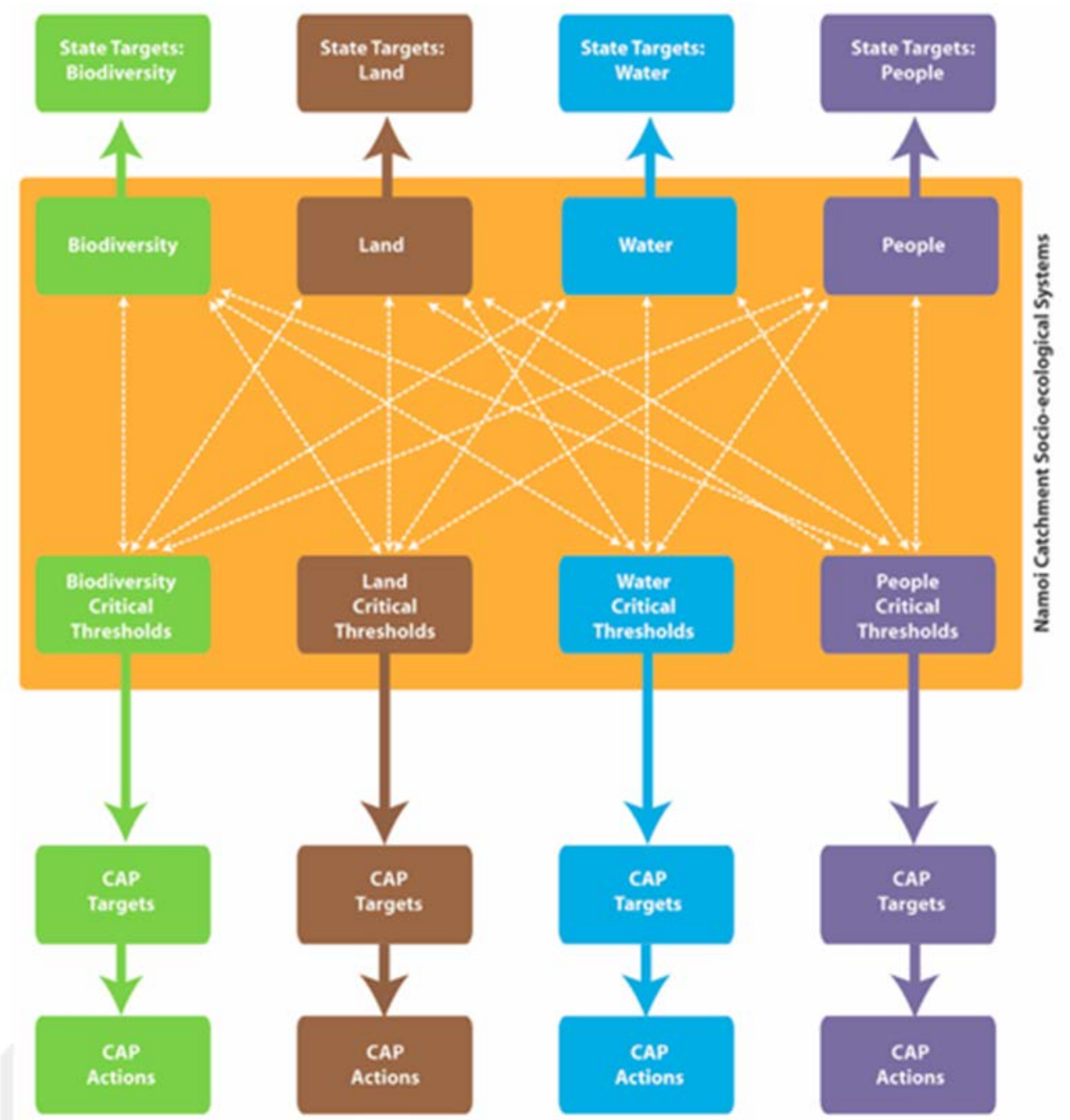

Figure 2: Conceptual model of the Namoi CAP. (Source: Namoi CMA [1].) 


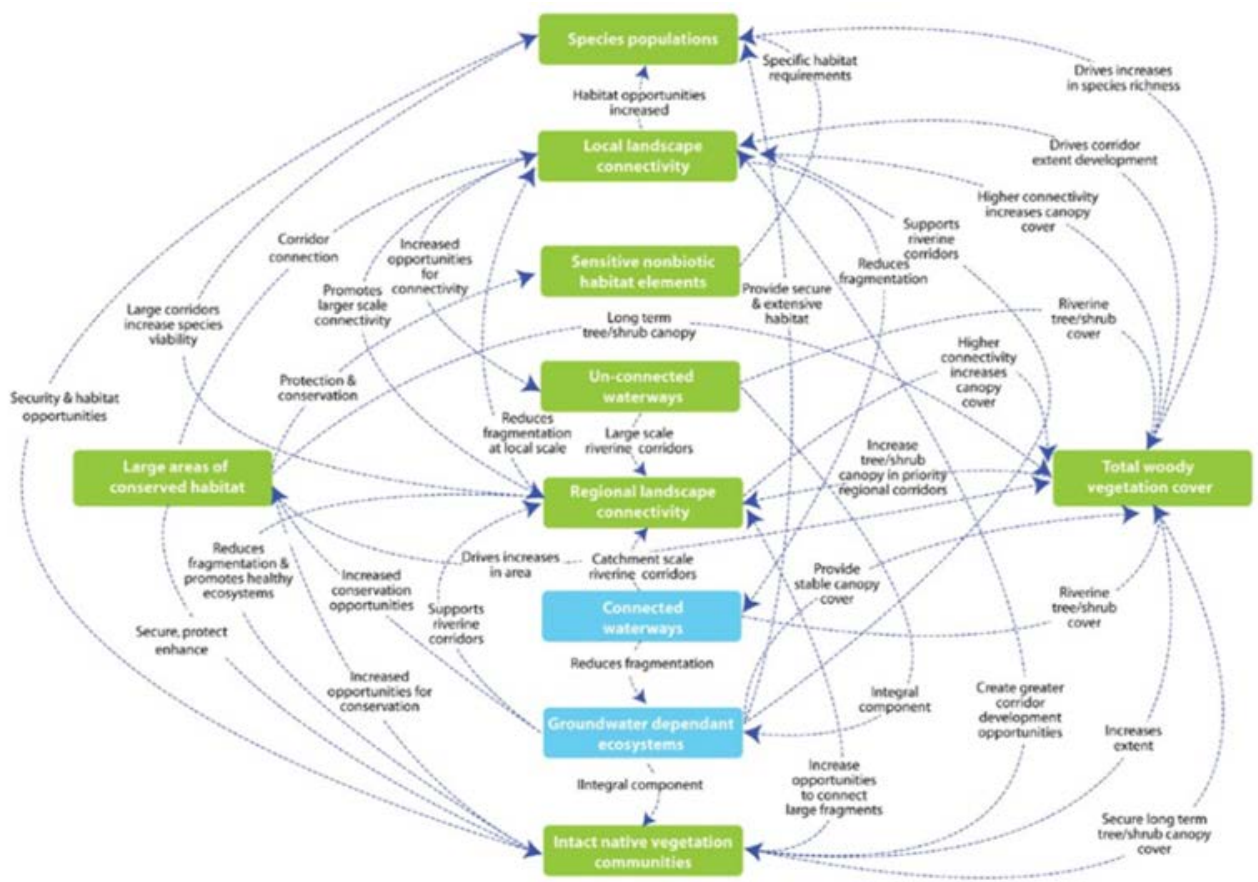

Figure 3: Example conceptual model - biodiversity. (Source: Namoi CMA [3].)

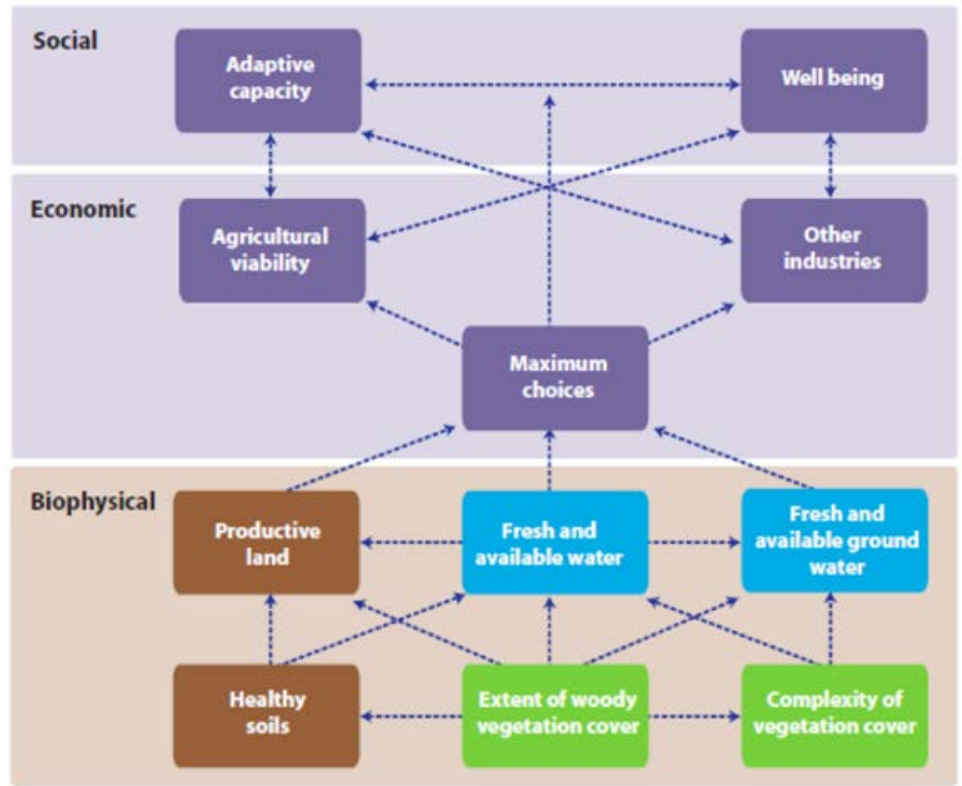

Figure 4: Conceptual model - Namoi Catchment critical functions. (Source: Namoi CMA [1].) 
Definition, trend in condition, impacts of continuing trend, drivers and threats, conceptual models, thresholds (known or suspected) and controlling variables were compiled for each asset. The assessment highlighted the most important critical assets and their functions in the Namoi Catchment as a social ecological system. Thresholds relating to those critical assets (i.e. those considered underpinning functions and contributing to multiple other assets) were described clearly and succinctly and carried forward into the CAP. They are the linkage between the evidence in the resilience assessment and the CAP.

\subsection{Draft targets based on critical thresholds, map priorities and align with state plans}

Once the most critical thresholds were defined, an assessment was made to establish what was required to avoid crossing them. These were then aligned to the relevant state targets, and defined in such as way so as to be measurable and specific. Some targets were then modified through the whole of government consultation and approval process (which was a step away from a resilience approach). Actions were then developed to help deliver on the target, and refined based on stakeholder input.

Following the identification of actions, a series of maps were produced to clearly show where investment should be directed to ensure that the relevant critical thresholds were not crossed. The intention was to present the outcomes of complex data and analysis in a simple and compelling way which was accessible to all stakeholders. All relevant state plans and priorities were reviewed to ensure alignment the closest possible alignment without undermining the overall coherence of the resilience-based CAP (see Fig. 5 for an example of mapping priorities).

\subsection{Consultation with stakeholders}

Consultation was undertaken throughout the process, to ensure (as much as possible) a whole of government and community endorsed CAP. This included a series of expert workshops, close consultation with local government organisations and a series of community

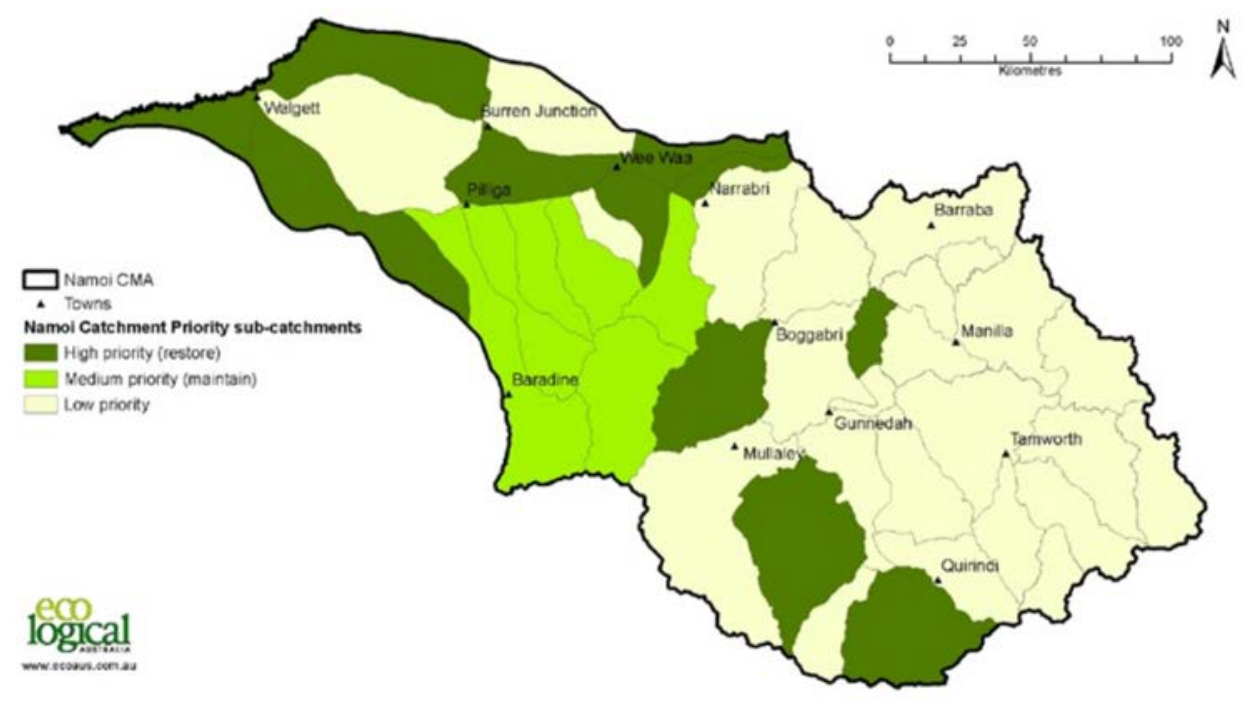

Figure 5: Priority sub-catchments for woody vegetation extent. (Source: Namoi CMA [1].) 
consultation workshops across the catchment. Supporting documentation was provided for all interested participants and stakeholders to enable them to get a better understanding of the CAP review process and resilience.

Evaluations were undertaken throughout to better understand how the resilience approach was received and viewed. The evaluation showed that the community overall understood resilience thinking to some degree and saw it as sensible (particularly amongst farmers). There was broad acceptance of the logic of the CAP and the resilience approach overall. Formal written submissions to a draft CAP were also received from the catchment community, experts, and other stakeholders. Changes to the CAP were made based on the feedback provided. NSW Government agencies provided combined feedback (in light of required standards and criteria) which was reviewed and incorporated where possible. Detailed discussions were held with all those who provided feedback to fully explore the issues raised and resolve them wherever possible.

\subsection{Adaptive management}

The CAP was designed to be a living document - regularly updated to reflect new knowledge, policy changes, and latest evidence. An update and review was undertaken in 2013 with a revised CAP, and revised resilience assessment of the catchment produced, along with two additional documents; a general resilience assessment (Namoi CMA 2013 [4]), and a subregional resilience assessment (Namoi CMA 2013 [5]) produced. This new information, along with the results of ongoing program, project and catchment asset monitoring and evaluations were used to inform the updated CAP.

\section{RESULTS}

The resilience-based CAP resulted in a much more sophisticated understanding of the complexity and dynamics of the Catchment as a social ecological system. A much tighter set of priorities for action were identified to maximise choices for the catchment community. A clear set of biophysical assets (productive lands, healthy soils, available of fresh surface and groundwater, and extent and complexity of native vegetation) and socio-economic assets (adaptive capacity, wellbeing, agricultural viability and other industries) interact to confer the Namoi Catchment's unique characteristics and provide the catchment community with maximum choices (Fig. 4). Through the resilience CAP development process, a set of 17 critical thresholds were identified, and a set of 10 targets designed to avoid crossing them (see Table 1). The critical assets were identified on the basis of conceptual models developed for each theme. 66 specific actions were developed to collaboratively deliver on these targets.

Three sub-regions (Tablelands, Slopes and Plains) were identified for the Catchment (Fig. 6). A set of conceptual models were developed to allow for a more targeted application of actions on ground based on the unique sub-regional context (Fig. 7).

\section{IMPLEMENTATION AND ADAPTIVE MANAGEMENT}

The CAP was a 10-year plan designed to drive and support collaborative efforts on-ground based on the variable annual funding available. Hence implementation planning was another important aspect of the approach. An investment planning flow chart was designed to develop annual priorities for implementation. The process was based on the overarching strategic level information contained with the CAP itself. All thresholds identified in the CAP were assessed in terms of their contribution to catchment function across all themes (categorised as high, medium or low). Proximity to the threshold was then assessed along with the trend for the highest priority assets and the time frame within which it was expected that the 
Table 1: Critical thresholds and target for the Namoi Catchment. (Source: Namoi CMA [1].)

\begin{tabular}{|c|c|c|}
\hline Theme & Critical thresholds & Targets \\
\hline $\begin{array}{l}\text { Biodiver- } \\
\text { sity }\end{array}$ & $\begin{array}{l}\text { - Woody vegetation cover at } 30 \% \text { in } \\
\text { cleared sub-catchments } \\
\text { - Woody vegetation cover at } 70 \% \text { in } \\
\text { intact sub-catchments } \\
\text { - Regional vegetation communities } \\
\text { maintain over } 30 \% \text { original extent } \\
\text { remaining } \\
\text { - Population size of individual } \\
\text { threatened species } \\
\text { - Habitat area for individual threatened } \\
\text { species or population } \\
\text { - Area of endangered or vulnerable } \\
\text { community } \\
\text { - Presence of individual invasive species } \\
\text { - Population extent of individual } \\
\text { invasive species }\end{array}$ & $\begin{array}{l}\text { 1. By } 2020 \text { there is an increase in native } \\
\text { vegetation extent and vegetation does } \\
\text { not decrease to less than } 70 \% \text { in less } \\
\text { cleared sub-catchments and } 30 \% \text { in over } \\
\text { cleared sub-catchments, and no further } \\
\text { regional vegetation community } \\
\text { decreases to less than } 30 \% \text {, as identified } \\
\text { by } 2010 \text { baseline. } \\
2 \text {. By } 2020 \text { maintain sustainable } \\
\text { populations of a range of native fauna } \\
\text { species by ensuring that no further } \\
\text { regional vegetation community } \\
\text { decreases to less than } 30 \% \text { extent as } \\
\text { identified by } 2020 \text { baseline. } \\
3 \text {. By } 2020 \text { contribute to the recovery of } \\
\text { priority viable threatened species, } \\
\text { populations and communities. } \\
4 \text {. By } 2020 \text { no new invasive species are } \\
\text { established in the catchment and the } \\
\text { spread of key emerging invasive plants } \\
\text { and animals is limited. }\end{array}$ \\
\hline Land & - Groundcover is at least $70 \%$ & $\begin{array}{l}\text { 1. By } 2020 \text { there is an improvement in } \\
\text { soil health as measured by an increase in } \\
\text { groundcover at the paddock, sub- } \\
\text { catchment and catchment scales }\end{array}$ \\
\hline Water & $\begin{array}{l}\text { - Surface water flow quantity is at } 66 \% \\
\text { of natural (pre-development) condition } \\
\text { with a sensitivity to natural frequency } \\
\text { and duration } \\
\text { - Geomorphic condition is good (against } \\
\text { benchmark condition) } \\
\text { - Recruitment of riparian vegetation is } \\
\text { higher than attrition of individual trees, } \\
\text { shrubs or groundcover species } \\
\text { - Agricultural and urban supply aquifers } \\
\text { do not cross into lower levels of } \\
\text { beneficial use regarding quality } \\
\text { - Alluvial aquifers are not drawn down } \\
\text { below long-term historical maximum } \\
\text { drawdown levels } \\
\text { - Groundwater levels do not drop below } \\
\text { the rooting depth of groundwater } \\
\text { dependent vegetation ecosystems } \\
\text { - Wetland is not drained, dammed or } \\
\text { otherwise physically modified }\end{array}$ & $\begin{array}{l}\text { 1. By } 2020 \text { there is an improvement in } \\
\text { the condition of those riverine } \\
\text { ecosystems that have not crossed defined } \\
\text { geomorphic thresholds as at the } 2010 \\
\text { baseline. } \\
\text { 2. By } 2020 \text { there is an improvement in } \\
\text { the ability of groundwater systems to } \\
\text { support groundwater-dependent } \\
\text { ecosystems and designated beneficial } \\
\text { uses. } \\
3 \text {. By } 2020 \text { there is an improvement in } \\
\text { the condition of regionally important } \\
\text { wetlands and the extent of those } \\
\text { wetlands is maintained. }\end{array}$ \\
\hline People & $\begin{array}{l}\text { There is no single set of clearly defined } \\
\text { thresholds relating to people, but the } \\
\text { generalities of building resilient social } \\
\text { capital by increasing adaptive capacity } \\
\text { and sustaining or improving wellbeing } \\
\text { are considered important priorities. }\end{array}$ & $\begin{array}{l}\text { 1. Natural resource management } \\
\text { decisions contribute to social wellbeing. } \\
2 \text {. There is an increase in the adaptive } \\
\text { capacity of the catchment community. }\end{array}$ \\
\hline
\end{tabular}




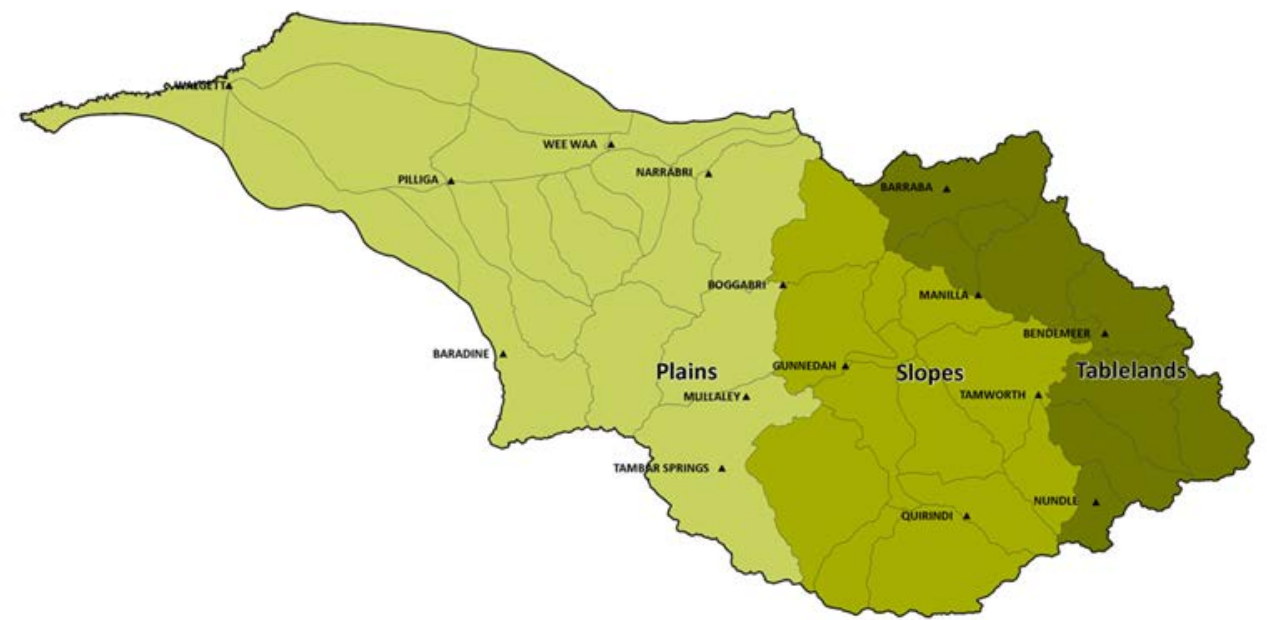

Figure 6: Namoi Catchment sub-regions. (Source: Namoi CMA 2013 [6].)

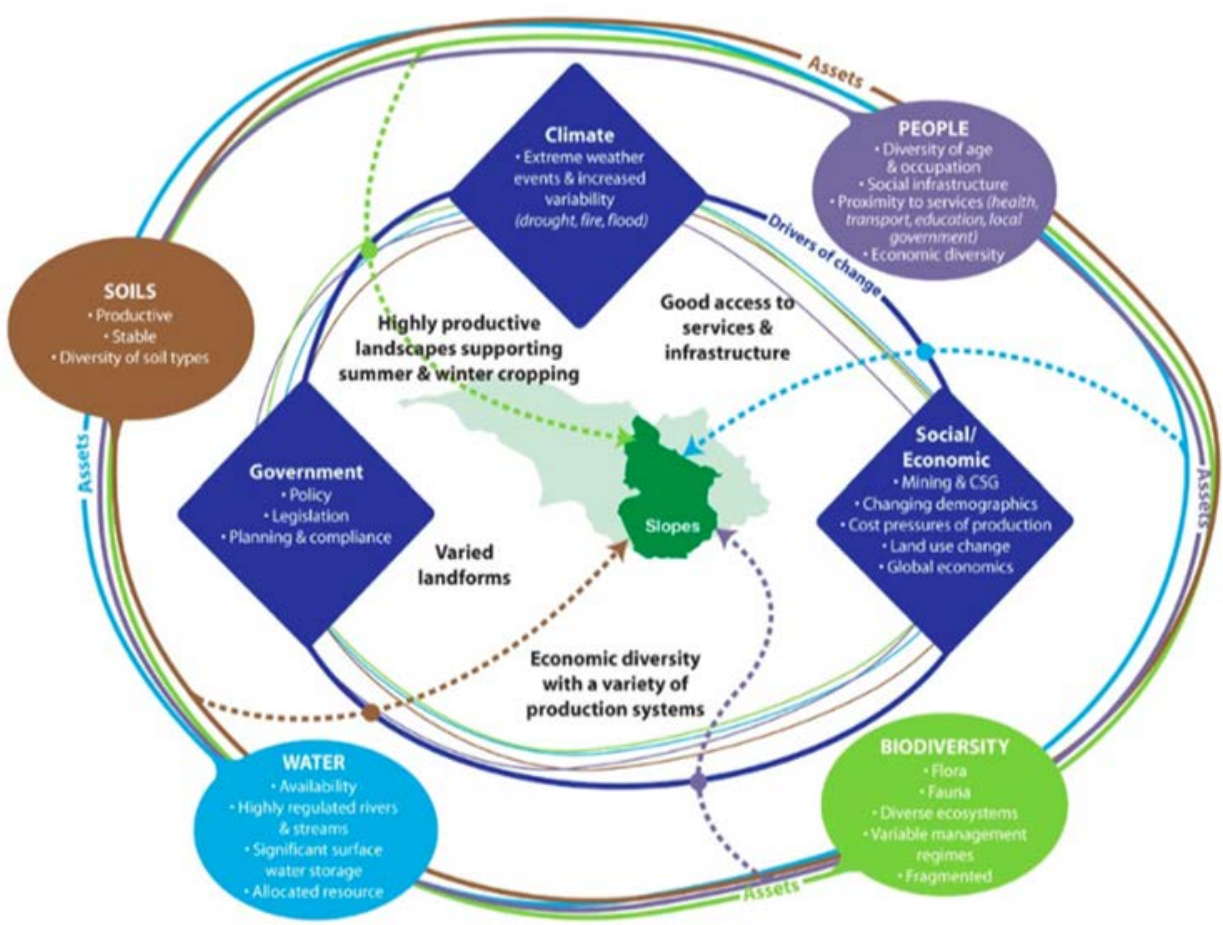

Figure 7: Sub-regional conceptual model - Slopes example. (Source Namoi CMA [6].) 


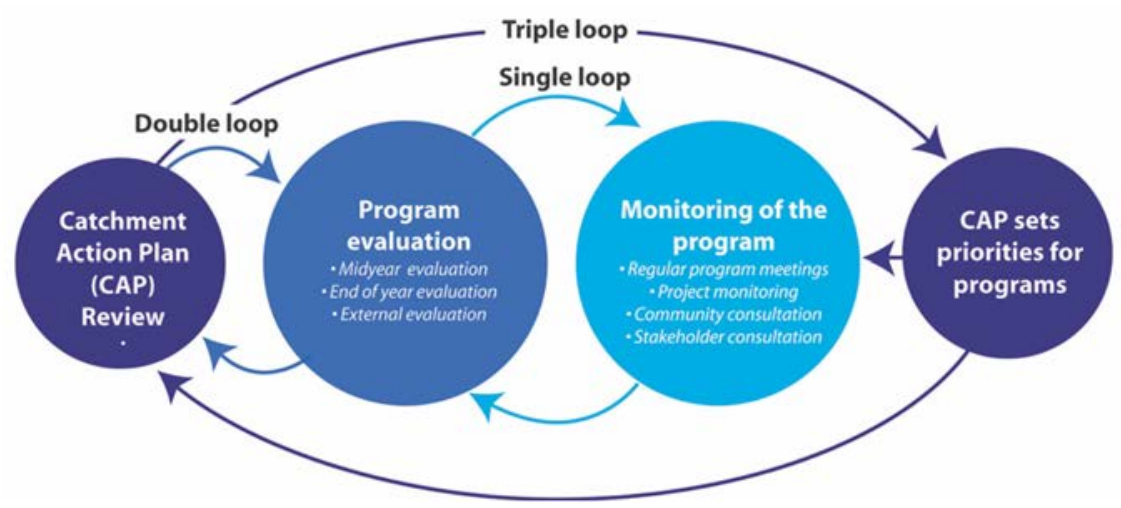

Figure 8: Triple loop learning in the Namoi CAP. (Source: Namoi CMA [1].)

threshold would be breached were the trend to continue. On that basis, initial program outlines were drafted and then assessed and ranked in terms of their impact; social, economic and environmental effects; achievability; time lag to benefits and costs.

Adaptive management is fundamental to resilience-based approaches and requires ongoing monitoring and evaluation. Thus a specific adaptive management strategy was developed to underpin CAP implementation. Adaptive management is critical to retest and recheck results and assumption as new information comes to light. It allows practitioners to track progress against thresholds and review interventions if they are proving ineffective. Monitoring and evaluation are the building blocks of adaptive management and triple loop learning underpinned the Namoi CAP approach.

The CAP was designed to be reviewed annually to include the latest results of new studies and analysis, the results of ongoing monitoring and evaluation, and to fill knowledge gaps as they were addressed. The approach taken was based on "triple loop learning" where the single loop is focussed on the objectives and to what extent they were achieved, the double loop asks if they were the right objectives, what is the evidence base, and how it aligns with new evidence, and the third loop looks at who was engaged, who set the agenda, and what processes were used (Fig. 8).

\section{STRENGTHS AND CHALLENGES OF THE APPROACH}

The resilience-based planning approach delivered a much more focussed and simplified set of priorities so as to ensure maximum future choices for the region. This allowed all stakeholders to focus on the few key issues that if not addressed potentially undermine the region's capacity to cope with future shocks and challenges. The resilience assessment resulted in the "uncluttering of the agenda" (as noted by a Namoi CMA Board member) leading to a much tighter set of priorities designed to make the most difference to the Catchment as a whole based on solid evidence. The adaptive management approach meant managers were able to take account of new understandings as they emerged. Another strength of using resilience-based approaches for natural resource management planning was a greater capacity amongst practitioners exposed to the approach to assess and analyse complex systems and priorities the most critical aspects based on system function.

Several challenges that emerged through the use of the resilience approach are also important to note. The most significant of these were: obtaining unanimous acceptance across stakeholders of current trends and trajectories based on best available evidence; thresholds 
being perceived as de facto development targets rather than a limit to be avoided; ensuring community and practitioner ownership and understanding of resilience concepts - to buffer against future policy shifts; integrating a resilience based plan with other existing policies and plans without undermining the coherence and strengths of the resilience approach; creating enough time and space for practitioners to engage with and embrace a new approach; and aligning longer term natural resource management goals with shorter term political cycles and objectives.

\section{SUBSEQUENT REFORMS AND THEIR IMPACT}

In 2014 following a change of State Government, CMAs, and CAPs were replaced, new boundaries designed (based on local government administrative boundaries rather than catchments) and a new organisation (NSW Local Land Services) tasked with combining the previous role of the CMAs and several other agencies in these new regions. CAPs were not continued, and new plans were developed based on new boundaries and responsibilities. Initially it appeared that much of the work undertaken was being set aside and old paradigms (based on traditional linear policy approaches) re-emerged. It is easy to assume that the resilience-based planning approach was abandoned in its entirety however a closer inspection reveals a more complex and nuanced result.

As noted by those involved in the first resilience CAP development process in NSW "you can't unthink what you've thought". Once practitioners and planners had learnt to think in terms of complex adaptive social-ecological systems, it was almost impossible to comfortably revert to more traditional planning paradigms. They had an increased capacity to consider and address complex adaptive systems due to their involvement in resilience based planning. This capacity has persisted despite subsequent reforms and changes. Leaders in the field note that working with practitioners who have been involved in applying resilience thinking to natural resource management planning, it is clear that they have a greater capacity to assess and analyse complex systems based on their experience with resilience planning

After a hiatus of several years - coping with the impact of the reforms and associated disruption to day to day operations, several regions have discretely returned to using a resilience-based approach. Over time planners and managers have come to value the resilience-based work and despite the current lack of centralised support for the resilience approach. Practitioners have continued to use the approach although the language and framing may be different so as to sit more easily with current planning and institutional frameworks that sit around natural resource management planning. The resilience planning community of practice (http://www.rpcop.org.au) hosted by the Australian Resilience Centre (http://www.ausresilience.com.au) has been an important element in supporting these practitioners and maintaining capacity in this resilience assessment and planning. As noted by one resilience expert "I'm having fundamentally different conversations with people and organisations" compared to before the resilience approach was embraced a decade ago.

Around Australia the result is likewise mixed with some regions letting go of the resilience approach given the lack of institutional support, some regions continuing to use it even without centralised support, whilst concurrently government agencies in other sectors and industries (such as the Australian Cotton Industry) have embraced the approach.

Previously regional planning was the main expression of resilience planning and main area of development for resilience practitioners. This has now shifted to other sectors beyond natural resource management, and to a different scale (state and national in particular). Some states (such as South Australia) are now exploring how to embed resilience principles at a state level to achieve resilient communities, industries and regions. Nationally resilience and 
adaptation are central to current Federal Government approaches particularly in the face of issues such as climate change.

\section{CONCLUSION}

Resilience based planning has proven itself to be a powerful tool - as much through the process itself as well as the results and outcomes achieved. Those involved in resilience assessment and planning have an increased capacity to deal with complex systems. Resilience based approaches have persisted (in various forms) despite a subsequent lack of institutional support. Practitioners know the old approaches have been inadequate to date and there is a need for a different approach and thinking. Hence there is a willingness to engage in new idea/conceptual framework. Often the barrier for individuals has been having the time to engage with new approaches given day to day demands on their time and resources.

Resilience is indeed a powerful conceptual framework and on that basis those who are given the opportunity to understand it and apply it are reticent to drop back to older more simplistic planning paradigms which fail to take account of the complexity of socialecological systems in the real world. It will be interesting to track how this progresses, particularly with further reforms under way in Australia, and other sectors beyond natural resource management exploring and using resilience as the basis for their planning.

\section{REFERENCES}

[1] Namoi, CMA, Namoi Catchment Action Plan, Namoi CMA: Gunnedah, 2013.

[2] Sellberg, M.M., Ryan, P., Borgstrom, S.T., Norstrom, A.V. \& Peterson, G.D., From resilience thinking to resilience planning: Lessons from practice. Journal of Environmental Management, 217, pp. 906-918, 2018. DOI: 10.1016/j.jenvman. 2018.04.012.

[3] Resilience Alliance, Assessing and Managing Resilience in Social-Ecological Systems: A Practitioner's Workbook, Resilience Alliance, 2010.

[4] Namoi CMA, Namoi Catchment Action Plan-Supplementary Document 1: The First Step - Preliminary Resilience Assessment of the Namoi Catchment, Namoi CMA: Gunnedah 2013.

[5] Namoi CMA, Namoi Catchment Action Plan-Supplementary Document 3: General Resilience Assessment of the Namoi Catchment, Namoi CMA: Gunnedah, 2013.

[6] Namoi CMA, Namoi Catchment Action Plan-Supplementary Document 2: SubRegional Resilience Assessment of the Namoi Catchment, Namoi CMA: Gunnedah, 2013. 